\title{
COMPARING ENVIRONMENTAL IMPACTS OF METAL ADDITIVE MANUFACTURING TO CONVENTIONAL MANUFACTURING
}

\author{
Van Sice, Corrie (1); \\ Faludi, Jeremy $(1,2)$ \\ 1: Dartmouth College Thayer School of Engineering; \\ 2: TU Delft Faculty of Industrial Design Engineering
}

\begin{abstract}
Metal additive manufacturing (AM) is revered for the design freedom it brings, but is it environmentally better or worse than conventional manufacturing? Since few direct comparisons are published, this study compared AM data from life-cycle assessment literature to conventional manufacturing data from the Granta EduPack database. The comparison included multiple printing technologies for steel, aluminum, and titanium. Results showed that metal AM had far higher CO2 footprints per $\mathrm{kg}$ of material processed than casting, extrusion, rolling, forging, and wire drawing, so it is usually a less sustainable choice than these. However, there were circumstances where it was a more sustainable choice, and there was significant overlap between these circumstances and aerospace industry use of metal AM. Notably, lightweight parts reducing embodied material impacts, and reducing use-phase impacts through fuel efficiency. Finally, one key finding was the irrelevance of comparing machining to AM per $\mathrm{kg}$ of material processed, since one is subtractive and the other is additive. Recommendations are given for future studies to use more relevant functional units to provide better comparisons.
\end{abstract}

Keywords: Additive Manufacturing, Metal 3D-printing, Sustainability, Life Cycle Assessment, Lightweight design

\section{Contact:}

Faludi, Jeremy

TU Delft

Industrial Design Engineering

Netherlands, The

j.faludi@tudelft.nl 


\section{INTRODUCTION}

Metal additive manufacturing (AM) is continuing to grow in popularity: the market reached $\$ 1$ billion in 2020 and is expected to grow by over 25\% annually for several years (Grand View Research, 2020). This year alone, one company using metal AM announced a $\$ 500 \mathrm{M}$ investment to scale production of 3D printed rocket engines (Sheetz, 2020). The technology offers many advantages over conventional manufacturing (CM)--making increasingly complex parts without special tooling, design optimization for more strength with less mass, and slimming supply chains. In some cases it provides environmental benefits, such as replacing the 855-part Denali turboprop engine with the only 12-part Catalyst engine (Dusen, 2017). Manufacturing with advanced materials is possible, like a cobalt-chromium ceramic alloy used to print jet engine nozzles (Beyer, 2014). However, AM often has much higher environmental impacts than CM, sometimes by 100x per kg of material processed (Gutowski et al., 2017). To improve sustainability, when should designers choose metal AM over CM, and when is it worse? Data is needed for industry leaders to make informed decisions in the growing environmental crisis.

To help provide some necessary data, this paper synthesizes existing environmental impact data of $\mathrm{CM}$ from the Granta database with life cycle assessment data of AM from recent literature. The Methods section describes the data gathering and synthesis. Then the Results and Discussion section provides quantitative comparisons of AM to machining, casting, extrusion, rolling, and forging. It also discusses impacts beyond the manufacturing stage of a part's life cycle, what assessment practices are needed for more relevant and meaningful comparisons, and suggests actionable design principles to improve sustainability. Finally, the Conclusion summarizes the findings and data gaps to list recommendations for future research.

\section{METHODS}

This study used two methods to establish comparisons of AM and CM: Environmental impact data for conventional manufacturing processes and common metals was drawn from the Granta CES Edupack materials database (Granta Design, 2020). Because such data was unavailable for metal additive manufacturing, a review of life cycle assessments in academic literature was performed. Data from these two sets of sources were then synthesized for comparison. Data gaps were also identified to provide recommendations for more relevant future comparisons.

\subsection{Database}

The Granta database is the most comprehensive and credible materials database in the world. It provides sophisticated tools to evaluate and visualize impact data for a variety of materials and manufacturing processes. The database was used to find Greenhouse Gas Emissions (GHG) intensity in $\mathrm{kg} \mathrm{CO} 2$ equivalents per $\mathrm{kg}$ of material processed and Cumulative Energy Demand intensity of source energy in MJ per kg of material processed.

Environmental impact data was gathered for a number of CM processes, including metal machining, casting, extrusion and foil rolling, roll forming and forging, and wire drawing. The manufacturing process impacts per $\mathrm{kg}$ of material were evaluated by type of material formed: mild steel, stainless steel, aluminium and titanium. Despite its common use in CM, mild steel data was later discarded because of a lack of sufficient data in AM literature to make comparisons. Approximately 50-100 variants were considered for each manufacturing process and material to account for different alloys and processing techniques. The maximum, minimum and mean values were then determined. Additionally, data was found for embodied material impacts, accounting for the consequences of mining, refining and ingot forming. Metal powder forming was also considered, a necessary process for preparing metals for AM, and used to calculate embodied material impacts for AM in this study. Whether the powder forming process chosen is identical to that used for AM is unknown; however, since the associated impacts were a small percentage of total AM impacts, greater precision was considered unnecessary for this study. 


\subsection{Literature review}

The Granta database was an excellent resource for conventional manufacturing data, but it unfortunately lacked sufficient information on additive manufacturing due to the comparatively few studies that exist. To facilitate comparisons of AM and CM, life cycle assessment (LCA) data was sought in academic journal articles, books, conference papers, and other sources. Three AM processes were considered: selective laser melting (SLM); electron beam melting (EBM); and directed energy deposition (DED), which includes direct metal deposition (DMD) and laser engineered net shaping (LENS) processes. SLM is a powder bed fusion method where a concentrated laser melts and fuses metal powder in fine layers. The process happens in an enclosed chamber with a flow of inert gas such as argon to control the melt pool and metal vapor generated under the laser. EBM is also a powder bed fusion process that uses an electron beam rather than a laser, and the build chamber is kept under vacuum. DED is not a powder bed process; rather, a tool deposits molten material along a build path by focusing a laser on a feed of material, either metal wire or flow of powder. DED machines resemble five-axis CNC mills with an extrusion-like tool-head. Data for binder jetting was also sought, but too few studies existed to draw reliable conclusions. Direct comparisons of AM to machining were especially sought, as this is the most common process substitution. Literature was gathered via Google Scholar and the Web of Science index by performing searches of these keywords: metal additive manufacturing; metal 3D printing; SLM; DED; DMD; LENS; EBM; binder jetting; steel; aluminium; titanium; machining; sustainability; LCA; life-cycle; CO2; energy; embodied energy; energy intensity; Cumulative Energy Demand; and combinations thereof. Citations from other literature reviews were also examined, notably Gutowski et al. (2017) and Kellens et al. (2017). Literature was selected for inclusion in the review if it listed climate impact and/or embodied energy to compare to Granta data. Literature without these measures was included only if it provided background context relevant for comparisons. Information about the influence of the product use-phase on overall environmental impacts was sought because significant reductions are possible depending on performance improvements enabled by AM designs.

\subsection{Synthesis}

Since few LCA studies exist that directly compare equivalent parts made by AM and CM, data from literature and the Granta database were calculated as $\mathrm{kg}$ of $\mathrm{CO} 2$ equivalent per $\mathrm{kg}$ of material processed to provide a basis for comparison. $\mathrm{KgCO} 2 \mathrm{eq} . / \mathrm{kg}$ is a widely accepted metric for quantifying environmental impacts across materials and processes. Using $\mathrm{kg}$ of material as the functional unit by which to measure environmental impacts is typical for not only manufacturing metals, but also manufacturing plastics and many other materials. This is because it enables universal comparisons, as all materials have mass, and is easy to measure and record and standardize compared to specific part geometries, which would vary widely by different circumstances. As LCA textbooks point out, no functional units are perfect, but poorly chosen ones can provide deceptive answers, and should be related to the function performed, hence the term (Vogtländer, 2013). Even for the same manufacturing process, impacts can obviously vary by part geometry and other factors. In the absence of an established standard reference part or set of parts, which would be more precise, $\mathrm{kgCO} 2 \mathrm{eq} . / \mathrm{kg}$ is a compromise that provides an intuitive understanding of how different manufacturing processes and material choices influence sustainability. It is the same functional unit used by the Granta database for this reason.

Measuring only $\mathrm{kg}$ of $\mathrm{CO} 2$ equivalents is, of course, also an imperfect metric, ignoring many categories of environmental impact. However, it is by far the most reported metric, and usually the only reported metric. Some studies did not even provide kg CO2 eq., instead reporting MJ of on-site energy demand, which is not actually an environmental impact, but is easy to measure. SimaPro LCA software was used to convert impacts given in $\mathrm{MJ}$ to $\mathrm{kgCO}$ eq. Site energy is a useful metric for determining the electricity directly consumed by a manufacturing process, but it does not account for the different impacts of producing that electricity, by wind, solar, coal burning, or hydro-power, for instance. Hence, the impact of using $1 \mathrm{MJ}$ of site energy was modelled in SimaPro as an average of regional US electric grid sources: Western Electricity Coordinating Council (WECC), Midwest Reliability Organization (MRO), Texas Reliability Entity (TRE), South East Reliability Corporation (SERC), and Northeast Power Coordinating Council (NPCC), using EcoInvent 2.0 data. 


\section{RESULTS AND DISCUSSION}

\subsection{Comparing database and literature}

Figure 1 compares $\mathrm{CM}$ data from the Granta database to AM data from literature. The graphs represent uncertainty as gradients from $100 \%$ opaque at the lowest recorded value to $100 \%$ transparent at the highest recorded value. This makes it difficult to see exactly where these regions begin and end, but that is intentional, as that is the definition of uncertainty. Numeric ranges are listed in the Y-axis text. The exceptions to defining the uncertainty as lowest and highest recorded value are the two items with only one citation; here, an uncertainty of $\pm 40 \%$ was added because that was the average range from lowest to highest of the other AM data. Sources cited in Figure 1a are 1: Kellens et al. (2011), 2: Baumers et al. (2011), 3: Baumers et al. (2010), 4: Kellens et al. (2017) (review paper, original source unclear), 5: Faludi et al. (2017), 6: Baumers et al. (2017), 7: Paris et al. (2016), 8: Priarone et al. (2017), 9: Jackson et al. (2016), 10: Wilson et al. (2014). Figure 2b uses data from Figure 1a but adds Granta data on embodied material impacts, including powder forming where appropriate for AM. Note the difference in the linear versus log scales of the graphs--this is due to the large contribution of embodied material impacts.
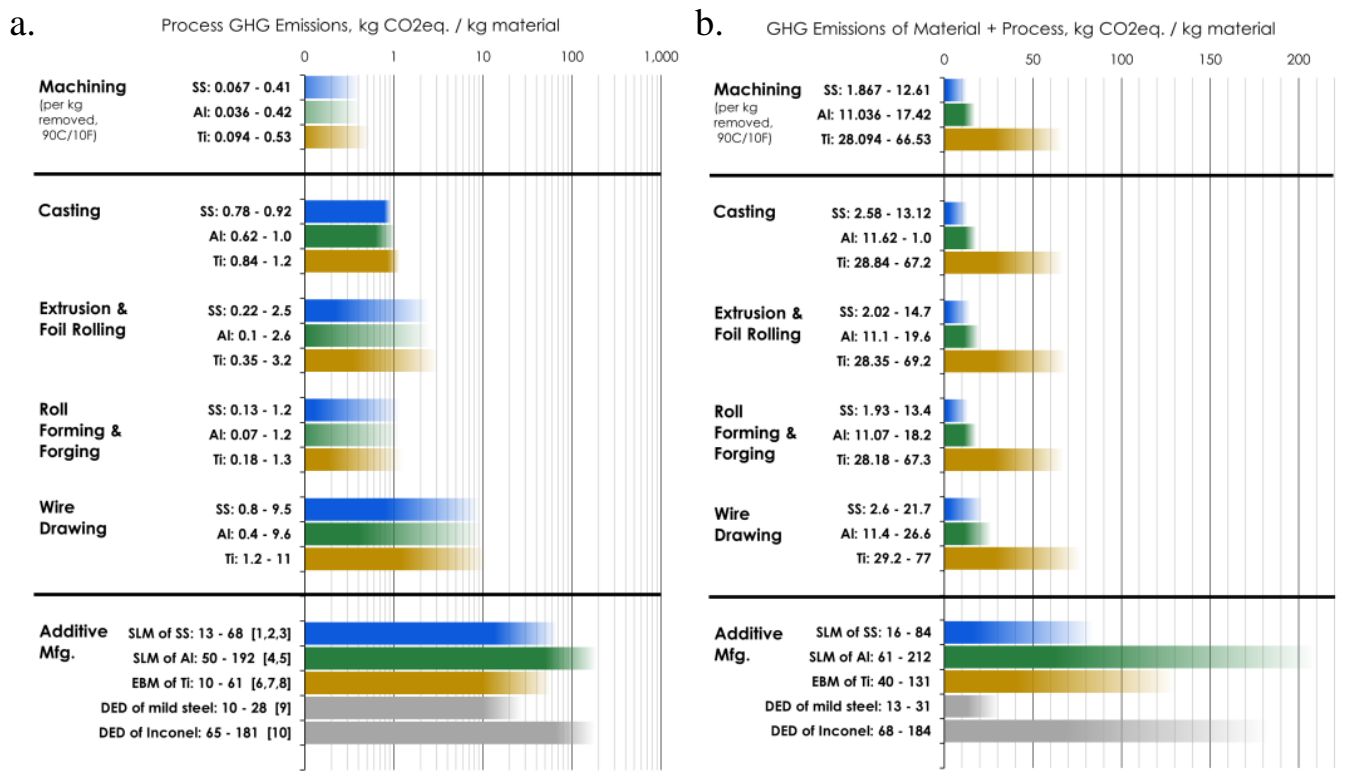

Figure 1a. impacts of $\mathrm{CM}$ and $\mathrm{AM}$ processes in $\mathrm{kg} \mathrm{CO}_{2}$ eq. per $\mathrm{kg}$ of material processed (log scale), and Figure 1b. impacts of processing plus embodied material impacts (linear scale). $S S=$ stainless steel, $A l=$ aluminium, $\mathrm{Ti}$ = titanium. Numbers in brackets are citations, listed in text. Gradients show ranges from maximum to minimum values. Shades differentiate material types.

Figure 1 shows that AM processes, in general, have a much higher carbon footprint per kg of material processed than $\mathrm{CM}$ when considering the manufacturing processes alone. For instance, in manufacturing stainless steel components, SLM impacts were 7.2-103x higher per $\mathrm{kg}$ of material processed than Granta data for casting, extrusion and foil rolling, roll forming and forging, and wire drawing processes. However, CM impacts changed significantly when the embodied impacts of stainless steel were included. The impacts of SLM of stainless steel, including embodied impacts of the material plus powder forming, were only 3.8-8.4x higher than these $\mathrm{CM}$ processes plus material impacts. Machining stainless steel ranged from $1.9-13 \mathrm{kgCO} 2 \mathrm{eq} . / \mathrm{kg}$ including material embodied impacts, but that is per $\mathrm{kg}$ of material removed, while AM and other CM processes are per $\mathrm{kg}$ added. Thus, part geometry can heavily influence machining's relative sustainability versus other processes. For this reason, a direct comparison of machining to AM and other CM processes cannot be made by $\mathrm{kg}$ of material processed. This topic is discussed in greater detail in the next section. 
Results for CM and AM of aluminium and titanium were consistent with those for stainless steel. Impacts of aluminium SLM were 20-714x higher per kg of material than Granta data for CM (Faludi, Baumers, et al., 2017; Kellens et al., 2017), or 6-8x higher including embodied material impacts. Titanium EBM impacts were 5.5-54x higher than CM (Baumers et al., 2017; Paris et al., 2016; Priarone et al., 2017), or only 1.4-1.7x including material impacts. These results are consistent with previous literature. Gutowski et al., 2017, concluded that AM's embodied electrical energy intensity (including non-metal materials) was 1-2 orders of magnitude higher than conventional machining and injection moulding, and processing speeds were 3 orders of magnitude smaller. Gutowski's results did not include embodied material impacts, so they are more dramatic than those reported above. This shows that AM is usually less sustainable than casting, extrusion, forging, and wire-drawing, when compared one-to-one. AM may be more sustainable if part mass is significantly reduced, it avoids tooling for small production runs, converts assemblies into fewer parts as mentioned in the introduction, or otherwise negates the need for multiple manufacturing processes. AM more often replaces machining than other processes, but the comparison is complicated and needs more studies that account for differences in part geometry, as will be discussed later.

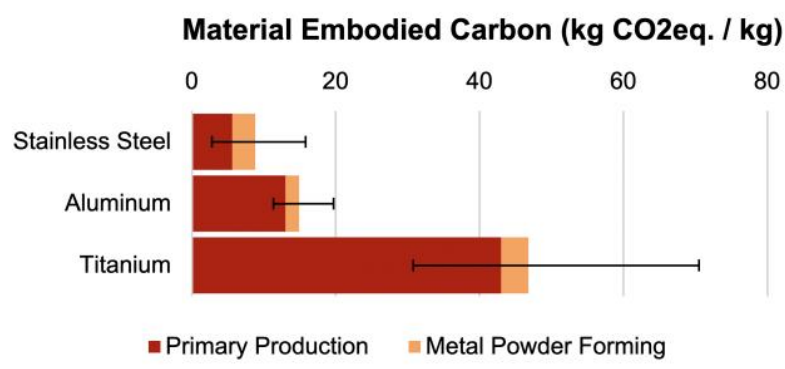

Figure 2. Embodied impacts in $\mathrm{kg} \mathrm{CO}_{2}$ eq. per $\mathrm{kg}$ of material from Granta, for primary production and metal powder forming. Total uncertainties for both values are shown as error bars, not gradients, to enable stacking of bars in the graph.

Figure 2 shows the embodied carbon footprint of materials used to calculate the values in Figure $1 \mathrm{~b}$ above. As mentioned in Methods, this data came from Granta; it was unknown whether the powder forming process listed is equivalent to AM powder forming, but it was a small enough percentage of impacts that further precision was not deemed necessary.

\subsection{More direct comparisons needed}

Since AM is an additive process and machining is reductive, measuring environmental impacts per $\mathrm{kg}$ processed makes a direct comparison between the two difficult. As mentioned above, impacts are highly influenced by part geometry: machining has an advantage for solid cubes, while AM has an advantage for hollow shells or lattices. Better comparisons could be made if assessors adopted a standard reference part or set of parts to measure impacts across an increasing variety of materials. One study by Priarone et al. (2017) provides a good example of a fair comparison of machining with EBM using titanium materials. Three different part geometries were considered: one solid, one partially hollow, and one thin-walled version. Despite EBM having higher processing impacts than $\mathrm{CM}$ in every case, the embodied material impacts of titanium decreased with the part mass for $\mathrm{AM}$ and remained the same for CM. Because titanium is an energy-intensive material to process, as shown in Figure 1 and Figure 2, the difference was enough to make EBM a more sustainable choice for the hollow geometries, especially the thin-walled version. Computing environmental impacts not per $\mathrm{kg}$ of material, but using reference parts as functional units, allowed an estimation of the cross-over point where AM of titanium became more sustainable than machining.

Even for comparisons of AM to the non-subtractive CM processes listed before (casting, extruding, etc.), more direct comparisons are needed to ensure that the LCAs include all processing stages necessary for a part to fulfil its function, such as surface finishing for part tolerancing or fluid flow. One study comparing investment casting of a turbine blade to SLM of Inconel found that SLM had lower environmental impacts (Torres-Carrillo et al., 2020), which contradicts the conclusions from Figure 1. While this study did not test different part geometries, it did include the finishing steps of grinding, machining surfaces, even marking and packaging of both the cast and SLM parts, providing 
a more comprehensive LCA of part production. These results might or might not hold for different part geometries or materials, and for other manufacturing methods. Interestingly, AM does not have to completely replace CM to provide a benefit: Prakash et al. (2021) found that the impacts of investment casting of an aluminium part could be improved by producing some tooling with AM instead of machining. Having more data like these and the Priarone study would enable more meaningful comparisons of different $\mathrm{AM}$ versus $\mathrm{CM}$ processes and materials.
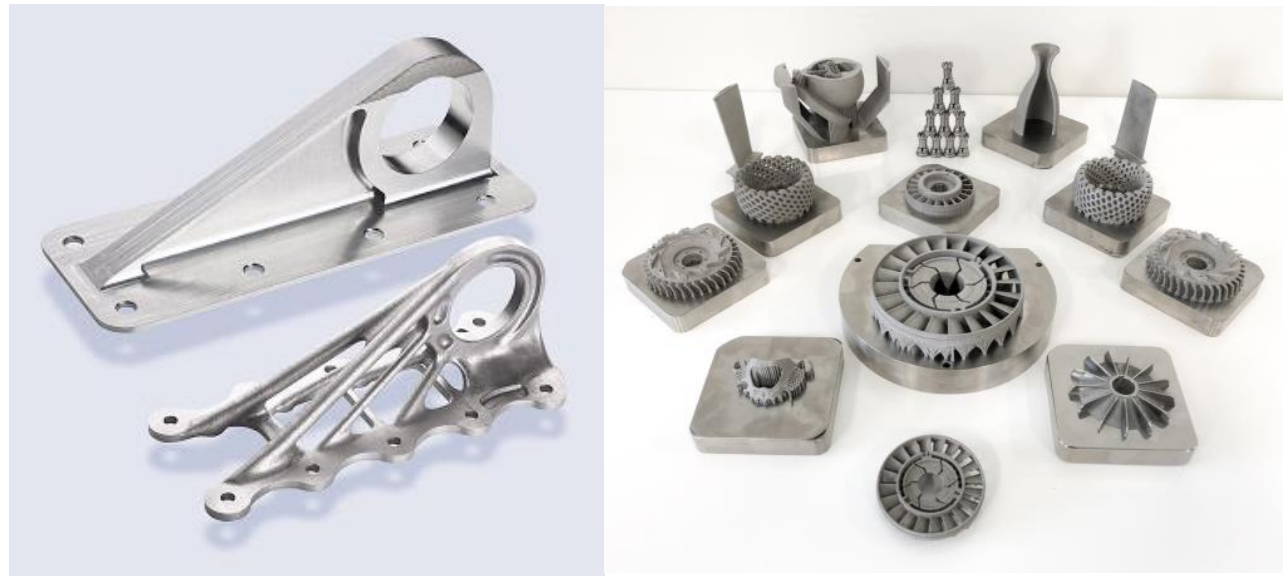

Figure 3a. (left) Two parts with equivalent functionality, which could be used as reference parts to fairly compare impacts of different manufacturing methods (Airbus Operations $\mathrm{GmbH}, 2016)$, and Figure 3b. (right) parts with complex interior geometries which are easier to produce by AM (Aurora Labs Ltd, 2019).

To provide fair comparisons, reference parts for functional units should represent typical parts produced by metal AM and competing manufacturing processes. We recommend industry, academic, and regulatory stakeholders convene to agree on a small set of reference parts to represent typical applications. On the one hand, it is desirable to have a universal reference part printed on various AM machine types to compare different technologies' impacts. In plastic AM, studies using a standardized reference part have compared all major print technologies and several material variants (Faludi et al., 2015; Shi and Faludi, 2020). On the other hand, a single part cannot represent the variation in impacts due to different technologies' specific applications.

Defining the functional unit as a specific part geometry (or set thereof) and assuming all such parts perform the exact same function is simple, but will also not enable fair comparisons between all options. Defining a specific function (e.g., carrying a given stress load and fatigue lifetime with given connection locations) would also open up comparisons of topologically-optimized geometries, whose forms would vary by manufacturing method, such as in Figure 3a. However, such definitions might be too narrow for widespread relevance, or too unwieldy to define and test. This is why multiple stakeholders should be consulted. The Priarone study described above achieved a valuable compromise, testing for optimization while remaining simple by choosing functional units that were a set of reference parts varying from solid to hollow. This was used to identify the cross-over point when one technology became more environmentally beneficial than the other. Given that manufacturing methods have different advantages for particular design requirements, reference parts should capture this variation.

For aerospace industry applications, a reference set should include one part with internal channels as in Figure $3 \mathrm{~b}$, because as the figure and its citation show, AM is often favoured for the ease of producing these features. Using CM for internal features can require assemblies or multiple processing steps, which is part of how the aforementioned redesign from Denali to Catalyst engine reduced part count so radically (Dusen, 2017). Another reference part should have high precision tolerances and surface finishes, because these are also common in aerospace, and machining easily fulfils these needs while AM parts can require post-processing steps to meet these requirements (increasing processing impacts). Reference parts should maximize the number of industry-relevant comparisons that can be made, and cover a variety of applications, but minimize demands of time and resources to study. Small parts will keep the investment burden low and enable testing of utilization efficiency, i.e., how well impacts can be amortized over the larger quantities produced at the full capacity of a machine's build volume. 
One example of reference parts could be both of the Airbus brackets from Figure 3a, since brackets are a common aerospace part and including both presents a range of geometry from solid with simple geometry to lightweight but complex geometry, which could find crossover points where AM is preferable to CM or vice-versa. Another example could be the complex chamber at the rear centre left of Figure 3b, for its internal chamber that AM can produce in one step but that would require several $\mathrm{CM}$ processes. Yet another example could be the turbine in the centre of Figure $3 \mathrm{~b}$, as turbines are common in aerospace and such a part would include machined surface finishing for AM and multiple manufacturing processes for $\mathrm{CM}$.

\subsection{Findings by life cycle stage}

Most LCAs of metal AM are quite limited in their scope; fair comparisons should be more comprehensive. Researchers usually assume metal AM processing energy dominates its total environmental impacts, because this is true for polymer AM; most studies cited for Figure 1 measure nothing else. Some studies also included consumable substances, such as argon for AM (Le Bourhis et al., 2014; Faludi, Baumers, et al., 2017; Yang et al., 2019) and oil lubricants for machining (Yang et al., 2019; Torres-Carrillo et al., 2020). While these studies found consumable impacts to be insignificant compared to energy, it is still more rigorous to measure them to verify their insignificance. Tooling can also be considered a consumable material; its impacts per part are high for small production runs, but fall in a hyperbolic curve as the number of parts produced rises, while AM's impacts per part do not change with production volume (Faludi, Cline-Thomas, et al., 2017). Thus, lack of tooling is only a benefit for small production runs.

Too few studies have included embodied impacts of materials and end-of-life, but there are some (Ingarao et al., 2018; Paris et al., 2016; Priarone et al., 2017). Paris (2016) did not clearly list ratios of print energy impacts to embodied material impacts, but Ingarao (2018) found that for aluminium, SLM print energy was always 10x larger than material impacts, and Priarone (2017) found that for titanium, EBM print energy impacts were only $70 \%$ of material impacts. Therefore, material impacts are sometimes vital to include. Despite the high process energy impacts of AM over CM, reductions in material use by minimizing part mass resulted in net savings compared to $\mathrm{CM}$ in some cases (Huang et al., 2016; Priarone et al., 2017), though not in others (Bockin and Tillman, 2019; Ingarao et al., 2018; Kellens et al., 2017; Yang et al., 2019). Material choice also influences process energy: SLM of aluminium necessitated higher energy use than EBM of titanium due to aluminium's high reflectance and thermal conductivity (Ingarao et al., 2018). Novel materials might also reduce metal printing energy; in polymer printing, novel materials have reduced print energy up to 75\% (Faludi et al., 2018).

Some papers considered the product use phase. Light-weighting parts using AM resulted in a significant reduction of environmental impacts in the use-phase for aerospace applications (Mohd Yusuf et al., 2019). Huang et al. (2017) calculated a global industry savings of 92 - 215 million metric tons of $\mathrm{CO} 2$ through the year 2050 when $9-17 \%$ of fleet-wide aircraft mass was replaced by lightweight AM parts. Most of these savings were attributed to using $6.4 \%$ less fuel over the aircrafts' life, but a small percentage of reduced impacts were due to material savings with AM over machining processes. Despite very positive results in aerospace applications, the trend does not seem to extend to automotive or rail industries. Kellens (2017) calculated savings per $\mathrm{kg}$ of weight reduction for multiple vehicle types, and impacts of AM compared to CM were not offset by fuel savings for passenger cars or trains. Each $\mathrm{kg}$ of mass saved in a long-distance commercial aircraft saved around 195,000 MJ of fuel energy, while the specific energy consumption of different metal printers ranged from 60 - $566 \mathrm{MJ}$ per $\mathrm{kg}$ of material processed. Mohd Yusuf et al. (2019) found similar numbers. Thus, even if AM replaced CM with zero energy impact per $\mathrm{kg}$, its extra manufacturing impacts would be quickly paid back by fuel savings. However, Kellens et al. also found that each $\mathrm{kg}$ of mass saved in a train only saved 1,000 - 1,050 MJ of fuel energy, and passenger cars only saved 48 - $85 \mathrm{MJ}$ per $\mathrm{kg}$ of weight saved. This 2,000x difference from airplanes was due to shorter automotive lifetimes, shorter distances travelled, and the physics of flight versus road travel. Yang (2019) found that for a specific road vehicle, higher AM impacts would only be paid back if it doubled part life and removed over 30\% of material. Because these respective industries are already aware of such weight savings, they already design parts differently--aviation parts are often lightweighted complex shapes. These complex shapes can sometimes be more efficiently produced by CM than AM, saving energy in manufacturing as well as use, as Huang et al. (2017) found. 
Only one metal AM study included the print machinery's embodied impacts (Faludi, Baumers, et al., 2017), though several studies include it for polymer AM (Faludi, Cline-Thomas, and Agrawala, 2017; Faludi et al., 2015; Shi and Faludi, 2020). Toxicity hazards posed to AM workers are rarely considered, but even in other industries, such hazards are usually considered separately from LCAs, so the topic is not discussed in detail here, but see Arrizubieta et al. (2020) for an investigation thereof.

Consistent across literature, maximizing printer utilization resulted in lower impacts per part because process energy is amortized, resulting in up to a $5 \mathrm{x}$ difference for metal, and higher for polymers (Baumers et al., 2011, 2013, 2016; Faludi, Baumers, et al., 2017; Shi and Faludi, 2020). In fact, most studies assumed maximum utilization in reported AM impacts, meaning most of the AM impacts in Figure 1 are optimistic. Note that because many metal AM processes can print multiple parts at once (e.g., SLM, EBM, and similar powder bed processes), utilization must be considered not only in terms of printer idle time but also idle print bed space. Maximizing spatial utilization can cut impacts per part up to 66\% (Baumers, 2011) or 52\% (Faludi, Baumers, et al. 2017), depending on part geometry and printer; larger print beds, of course, provide larger savings.

\subsection{Choosing additive or conventional manufacturing}

To summarize, metal AM can be a more sustainable choice than CM in many circumstances, but it should not be considered more sustainable by default. It is often less sustainable due to its high specific energy demand, as shown in Figure 1. Designers should thus consider when to use AM versus CM. Based on the results above, AM is often a more sustainable choice when:

- AM-enabled lightweighting improves use-phase impacts and those impacts dominate overall lifetime impacts (e.g., much aviation).

- $\quad$ AM consolidates many manufacturing processes into a single step (including part consolidation).

- Materials with high embodied impacts are saved (e.g., titanium).

- Very low part quantities are required and extensive tooling is avoided (e.g., custom medical implants).

These results are supported by Kellens et al.'s (1027) list of potential AM benefits. They also point out the converse of the list above: namely, that AM is likely worse than $\mathrm{CM}$ for mass production and for direct substitution of a single CM process (e.g., replacing extrusion with SLM), and that benefits are uncertain for light-weighting automotive parts or consolidating only a few $\mathrm{CM}$ processes. The circumstances listed above do not guarantee that AM is better than CM for a specific situation. Designers should also consider general principles of design for sustainable AM part production, including material choice, machine utilization, and other factors. Whether replacing CM or not, designers, printer operators, and printer producers can design for sustainable metal AM by following these guidelines:

- Design to minimize print time when energy impacts dominate (e.g., aluminium SLM); this can include designing for maximal spatial utilization (filling print beds).

- Design to minimize material use when material impacts dominate (e.g., titanium EBM).

- Design to maximize utilization of printer build volume, for energy efficiency.

- Minimize printer idle time and embodied impacts by sharing print jobs among fewer printers.

- Choose materials to minimize embodied impacts, when possible without sacrificing functionality.

- Choose materials to minimize processing energy, like those with low reflectivity or melt points, when possible without sacrificing functionality.

- AM machine manufacturers should work towards low-impact combinations of materials, processing, and build environments.

\section{CONCLUSION}

When metal AM life-cycle data from literature was compared to metal CM data from the Granta materials database, AM often had an order of magnitude or two higher carbon footprint per $\mathrm{kg}$ of material than casting, extrusion, rolling, and wire drawing processes. When including impacts embodied in the materials, AM multiplied impacts by 1.4-8x. However, this is often not a fair comparison, as AM can build some parts in one step that would require multiple CM steps. In addition, the comparison of AM to machining is complicated by a fundamental difference in the fabrication process: during AM, material is added to produce parts, but during machining, material is removed from a stock piece. This 
makes a comparison by $\mathrm{kgCO} 2 \mathrm{eq} / \mathrm{kg}$ material highly dependent on the part geometry, because process energy for machining will be lower when less material is removed, as for solid parts. In contrast, metal AM can have lower manufacturing impacts than machining when material use is low, such as for thinwalled or lattice structured parts; especially for high embodied impact materials, such as titanium.

Therefore, future studies should perform LCA comparisons where the functional unit is not $\mathrm{kg}$ of material processed, but a standard reference part (or set of parts), utilization scenario(s), and system boundaries. The reference part(s) should simulate the most common likely use case(s). Utilization scenarios should include both temporal (idle time) and spatial (print bed space) variables, and should include both maximum utilization and less-optimal but common scenarios from industry. System boundaries should include not only print energy, but all other processing energy required for the finished part (e.g., surface finishing for AM or multiple manufacturing stages for CM where needed), material impacts, consumable materials (e.g., argon for AM, lubricant oil for machining, tooling for extrusion), and use phase impacts (especially crucial for aerospace applications). Ideally they would even include the impacts of producing the AM printer or CM machine tools. Standardizing reference parts, utilization scenarios, and system boundaries would enable more precise and meaningful comparisons across increasingly varied material and manufacturing process types, even allowing for identifying transition points where the more sustainable choice shifts from one process to another. These reference parts, utilization scenarios, and system boundaries should likely be chosen by a gathering of industry, academic, and regulatory stakeholders to ensure relevance and widespread acceptance.

Even with the data available today, some clear trends are visible in AM processing methods with higher and lower environmental impacts, and a simple set of guidelines was listed to increase sustainability of AM operations and printer design. It would be exciting to see if metal AM processes could be optimized to be more sustainable than conventional manufacturing by default, not just in special cases.

\section{ACKNOWLEDGMENTS}

Thanks to the Additive Manufacturer Green Technology Association for their support of this project.

\section{REFERENCES}

Airbus Operations GmbH. (2016), “Ahead! Topologically optimised components in aviation”, Airbus Operations GmbH, available at: https://www.objective3d.com.au/wp-content/uploads/2016/11/Application-GuideAerospace.pdf (accessed 24 November 2020).

Arrizubieta, J.I., Ukar, O., Ostolaza, M. and Mugica, A. (2020), "Study of the Environmental Implications of Using Metal Powder in Additive Manufacturing and Its Handling”, Metals, Multidisciplinary Digital Publishing Institute, Vol. 10 No. 2, p. 261.

Aurora Labs Ltd. (2019), "Collection of RMP Alpha prototype prints", available at: https://www.auroralabs3d.com (accessed 3 December 2020).

Baumers, M., Dickens, P., Tuck, C. and Hague, R. (2016), "The cost of additive manufacturing: machine productivity, economies of scale and technology-push", Technological Forecasting and Social Change, Vol. 102, pp. 193-201.

Baumers, M., Tuck, C., Hague, R., Ashcroft, I. and Wildman, R. (2010), “A Comparative Study of Metallic Additive Manufacturing Power Consumption”, Solid freeform fabrication symposium, Austin, TX, p. 11.

Baumers, M., Tuck, C., Wildman, R., Ashcroft, I. and Hague, R. (2011), "Energy inputs to additive manufacturing: does capacity utilization matter?”, EOS, Vol. 1000 No. 270, pp. 30-40.

Baumers, M., Tuck, C., Wildman, R., Ashcroft, I. and Hague, R. (2017), "Shape Complexity and Process Energy Consumption in Electron Beam Melting: A Case of Something for Nothing in Additive Manufacturing?", Journal of Industrial Ecology, Wiley, Hoboken, Vol. 21, pp. S157-S167.

Baumers, M., Tuck, C., Wildman, R., Ashcroft, I., Rosamond, E. and Hague, R. (2013), “Transparency Built-in”, Journal of Industrial Ecology, Vol. 17 No. 3, pp. 418-431.

Beyer, C. (2014), "Expert View: Strategic Implications of Current Trends in Additive Manufacturing", Journal of Manufacturing Science and Engineering, Vol. 136, pp. 064701-1.

Bockin, D. and Tillman, A.-M. (2019), "Environmental assessment of additive manufacturing in the automotive industry”, Journal of Cleaner Production, Elsevier Sci Ltd, Oxford, Vol. 226, pp. 977-987.

Dusen, M.V. (2017), “GE's 3D-Printed Airplane Engine Will Run This Year | GE News”, 19 June, available at: https://www.ge.com/news/reports/mad-props-3d-printed-airplane-engine-will-run-year (accessed 8 September 2020). 
Faludi, J., Baumers, M., Maskery, I. and Hague, R. (2017a), "Environmental Impacts of Selective Laser Melting: Do Printer, Powder, Or Power Dominate?”, Journal of Industrial Ecology, Vol. 21 No. S1, pp. S144-S156.

Faludi, J., Cline-Thomas, N. and Agrawala, S. (2017b), The Next Production Revolution: Implications for Governments and Business. Ch.5: $3 D$ Printing and Its Environmental Implications, Organisation for Economic Cooperation and Development (OECD), Paris.

Faludi, J., Hu, Z., Alrashed, S., Braunholz, C., Kaul, S. and Kassaye, L. (2015), 'Does Material Choice Drive Sustainability of 3D Printing?”, International Journal of Mechanical, Aerospace, Industrial and Mechatronics Engineering., Vol. 9 No. 2, p. 8.

Faludi, J., Van Sice, C.M., Shi, Y., Bower, J. and Brooks, O.M.K. (2018), "Novel Materials Can Radically Improve Whole-System Environmental Impacts of Additive Manufacturing”, Journal of Cleaner Production, Vol. 212, pp. 1580-1590.

Grand View Research. (2020), “3D Printing Metal Market Size, Share | Industry Report, 2020-2027”, Market Analysis Reports, June, available at: https://www.grandviewresearch.com/industry-analysis/3d-metalprinting-market (accessed 2 September 2020).

Granta Design. (2020), “Granta CES EduPack”, Granta Design Limited, available at: http://www.grantadesign.com/education/datasheets/ABS.htm (accessed 19 January 2015).

Gutowski, T., Jiang, S., Cooper, D., Corman, G., Hausmann, M., Manson, J.-A., Schudeleit, T., et al. (2017), "Note on the Rate and Energy Efficiency Limits for Additive Manufacturing", Journal of Industrial Ecology, Vol. 21 No. S1, pp. S69-S79.

Huang, R., Riddle, M., Graziano, D., Warren, J., Das, S., Nimbalkar, S., Cresko, J., et al. (2016), "Energy and emissions saving potential of additive manufacturing: the case of lightweight aircraft components", Journal of Cleaner Production, Vol. 135, pp. 1559-1570.

Ingarao, G., Priarone, P.C., Deng, Y. and Paraskevas, D. (2018), "Environmental modelling of aluminium based components manufacturing routes: Additive manufacturing versus machining versus forming", Journal of Cleaner Production, Vol. 176, pp. 261-275.

Jackson, M.A., Van Asten, A., Morrow, J.D., Min, S. and Pfefferkorn, F.E. (2016), “A comparison of energy consumption in wire-based and powder-based additive-subtractive manufacturing", Procedia Manufacturing, Elsevier, Vol. 5, pp. 989-1005.

Kellens, K., Baumers, M., Gutowski, T.G., Flanagan, W., Lifset, R. and Duflou, J.R. (2017), “Environmental Dimensions of Additive Manufacturing: Mapping Application Domains and Their Environmental Implications", Journal of Industrial Ecology, Vol. 21 No. S1, pp. S49-S68.

Kellens, K., Yasa, E., Renaldi, R., Dewulf, W., Kruth, J.-P. and Duflou, J. (2011), "Energy and Resource Efficiency of SLS/SLM Processes (Keynote Paper)", SFF Symposium 2011, pp. 1-16.

Le Bourhis, F., Kerbrat, O., Dembinski, L., Hascoet, J.Y. and Mognol, P. (2014), "Predictive Model for Environmental Assessment in Additive Manufacturing Process", Procedia CIRP, 21 st CIRP Conference on Life Cycle Engineering, Vol. 15, pp. 26-31.

Mohd Yusuf, S., Cutler, S. and Gao, N. (2019), "Review: The Impact of Metal Additive Manufacturing on the Aerospace Industry”, Metals, Multidisciplinary Digital Publishing Institute, Vol. 9 No. 12, p. 1286.

Paris, H., Mokhtarian, H., Coatanéa, E., Museau, M. and Ituarte, I.F. (2016), "Comparative environmental impacts of additive and subtractive manufacturing technologies”, CIRP Annals, Vol. 65 No. 1, pp. $29-32$.

Prakash, C., Singh, S., Kopperi, H., Ramakrihna, S. and Mohan, S.V. (2021), "Comparative job production based life cycle assessment of conventional and additive manufacturing assisted investment casting of aluminium: A case study", Journal of Cleaner Production, Vol. 289, p. 125164.

Priarone, P.C., Ingarao, G., Lorenzo, R. di and Settineri, L. (2017), "Influence of Material-Related Aspects of Additive and Subtractive Ti-6Al-4V Manufacturing on Energy Demand and Carbon Dioxide Emissions", Journal of Industrial Ecology, Vol. 21 No. S1, pp. S191-S202.

Sheetz, M. (2020), "Relativity Space adds $\$ 500$ million to 'war chest' for scaling production of 3D-printed rockets”, CNBC, 23 November, available at: https://www.cnbc.com/2020/11/23/relativity-space-builds-warchest-for-building-.html (accessed 4 December 2020).

Shi, Y. and Faludi, J. (2020), "Using Life Cycle Assessment To Determine If High Utilization Is The Dominant Force For Sustainable Polymer Additive Manufacturing”, Additive Manufacturing, Vol. 35, p. 101307.

Torres-Carrillo, S., Siller, H.R., Vila, C., López, C. and Rodríguez, C.A. (2020), "Environmental analysis of selective laser melting in the manufacturing of aeronautical turbine blades", Journal of Cleaner Production, Vol. 246, p. 119068.

Vogtländer, J. (2013), LCA: A Practical Guide for Students, Designers \& Business Managers, VSSD, Delft NL.

Wilson, J.M., Piya, C., Shin, Y.C., Zhao, F. and Ramani, K. (2014), "Remanufacturing of turbine blades by laser direct deposition with its energy and environmental impact analysis", Journal of Cleaner Production, Vol. 80, pp. 170-178.

Yang, S., Min, W., Ghibaudo, J. and Zhao, Y.F. (2019), "Understanding the sustainability potential of part consolidation design supported by additive manufacturing", Journal of Cleaner Production, Vol. 232, pp. $722-738$. 